\title{
Epistemic modality, particles and the potential optative in Classical Greek
}

\author{
Ezra la Roi \\ Vrije Universiteit Amsterdam \\ ezralaroi@gmail.com
}

\begin{abstract}
This paper challenges the commonly held view that the Classical Greek potential optative has a subjective epistemic semantics, the result of a conceptual confusion of subjectivity and epistemic modality inherited from our standard grammars. I propose that this view becomes less convincing when the optative's unique interaction with the subjective particles $\hat{\eta}$ and $\alpha \rho \alpha$ is incorporated into the analysis. Rather, the potential optative has a non-subjective epistemic semantics presenting an epistemic judgment as interpersonally accessible to the conversational participants. Frequencies of combination with $\hat{\eta}$ and $\alpha \dot{p} \alpha$, linguistic tests for subjectivity on the potential optative, and contrastive contextual analyses corroborate this view.
\end{abstract}

\section{Keywords}

potential optative - epistemic modality - subjectivity - particles $-\hat{\eta}-\ddot{\alpha} \rho \alpha$

Currently, the domain of Ancient Greek particles persists as a favoured object of research among Ancient Greek linguists, leading to a steady decrease in the number of unanswered questions that the particles raise. ${ }^{1}$ Nevertheless, a question that in my view has been somewhat left unexplored with regard to the particles is how they interact with other linguistic domains such as tense, aspect,

1 Cf., for example, Bonifazi et al. (2016).

(C) EZRA LA ROI, $2019 \mid$ DOI:10.1163/15699846-01901002

This is an open access article distributed under the terms of the prevailing CC-BY-NC license at the time of publication. 
modality and mood..$^{2}$ This lack may be due to the influence of Denniston's seminal work (especially for modality and mood); for despite his maximalist description of the particle's uses, he did not distinguish among different uses with mood types or among specific uses of moods. Recently, two fundamental improvements to Denniston's approach have been suggested: Thijs (2017) has convincingly argued that a distinction between uses in non-assertive and assertive speech acts is relevant for the functional description of the Ancient Greek particle $\mu \eta^{\prime} v$, and Revuelta Puigdollers (2017: 24) has suggested that particles "mark or modify both the illocutionary force and the modality expressed by the clause." He also summarized the compatibility of particles with specific sentence types. This paper proposes to take these ideas one step further by arguing that the way that certain particles combine with specific mood uses can tell us more about that mood use. More specifically, this paper will highlight the unique contribution of the two subjective particles $\hat{\eta}$ and $\ddot{\alpha} \rho \alpha$ to the identification of the semantics of the potential optative in Classical Greek. ${ }^{3}$ I chose these particles because of their remarkable distribution with the potential optative. ${ }^{4}$ Currently, the difference in meaning of the potential optative when it is and when it is not combined with subjective particles such as $\hat{\eta}$ (and $\left.\alpha^{\prime} \rho \alpha\right)$ is still to be explained; see example (1):

(1) Orestes:

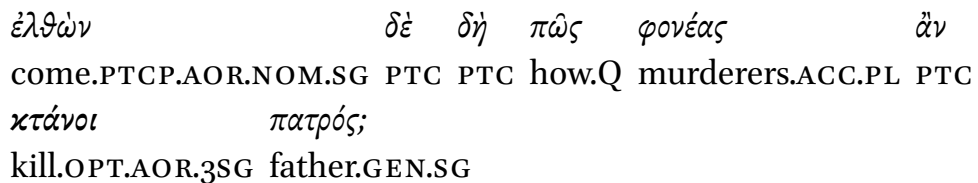

2 To illustrate, no article in the collections of Rijksbaron (1997) or Logozzo \& Poccetti (2018) discusses the interaction of these domains. However, recent attempts to investigate the interaction of particles with mood/modality are Revuelta Puigdollers (2017) and Tronci (2017). See Allan $(2009 ; 2013 \mathrm{~b})$ for the relevance of particles in distinguishing different text types and modes of narration. Finally, Denizot (2011: 82-86) briefly discusses particles that are susceptible to occurring with directives, but she does not perform an in-depth assessment of their influence on the meaning of the co-occurring mood.

3 Throughout I use the term 'potential optative' to refer to an optative mood form in a main clause (most often combined with the particle $\alpha \dot{\alpha} v$ ) that receives an interpretation of potentiality.

4 Another reason is that the potential optative has been systematically disregarded by Denniston (1954). He only discusses wishes separately, treating potential optatives under the same headers as indicatives. Furthermore, the wish optative also occurs with both particles, suggesting that it has a similar non-subjective epistemic meaning, but this matter lies outside the scope of this article and is discussed in la Roi forthc. 
Electra:

$\tau 0 \lambda \mu \omega \nu$

$\dot{v} \pi^{\prime} \dot{\chi} \chi \vartheta \rho \omega \hat{\nu}$

oí $\varepsilon \tau 0 \lambda \mu \eta^{\prime} \vartheta$

dare.PTCP.PRS.NOM.SG by enemies.GEN.PL what endure.AOR.3SG

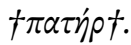

father.NOM.SG

Orestes:

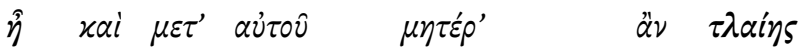

PTC also with he.GEN.SG mother.ACC.SG PTC dare.OPT.AOR.2SG

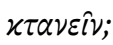

kill.INF

Electra:

$\tau \alpha \dot{\tau} \hat{\omega} \iota \quad \gamma \varepsilon \quad \pi \varepsilon \lambda \varepsilon \dot{x \varepsilon l} \tau \hat{\omega} \iota \quad \pi \alpha \tau \dot{\eta} \rho \quad \dot{\alpha} \pi \dot{\omega} \lambda \varepsilon \tau$.

the.same.DAT.SG PTC axe.DAT.sg the.DAT father.NOM.SG die.3sG.AOR

Orestes: But if he does come, how would he kill his father's murderers?

Electra: By showing the same boldness his enemies once showed.

Orestes: Surely you would also have the hardihood to kill your mother with his help?

Electra: Yes, with the same axe with which my father met his death! ${ }^{5}$ (E. El. 274-277)

The particles $\hat{\eta}$ and $\ddot{p} \alpha$ have been, I think, convincingly classified as markers of subjective semantic meaning by Allan (2015) using the elaborate, hierarchically layered organization of the clause from Functional Discourse Grammar. ${ }^{6}$ Consequently, these particles can tell us something about the semantics of the moods with which they occur. However, the semantics of the potential optative has been commonly characterized as subjective, as well (e.g., Drummen 2013: 74). An alternative explanation would thus be desirable.

The remainder of this paper is devoted to outlining a non-subjective approach to the semantics of the potential optative to offer such a potential explanation. As I emphasize further on as well, my proposal thus only concerns the semantics of the potential optative, not the many pragmatic values of utterances with the potential optative. After examining the previous litera-

5 I used the most recent ост-editions for the texts in this article. My translations are based on the most recent Loeb translations.

6 For Functional Discourse Grammar, see Hengeveld \& Mackenzie (2008), and for a diachronic version Allan (2018). 
ture on the potential optative and the particles found with it (Section 2), I detail a non-subjective approach to epistemic modality (Section 3), and the potential optative in particular (Section 4), which can account for the combinations with these particles as well. Subsequently, I present three types of support for this approach: (1) the low frequency of the potential optative combining with the subjective particles $\hat{\eta}$ and $\alpha$ p $\alpha$ (Section 5); (2) linguistic tests for subjectivity on the potential optative (Section 6); and (3) contextual analysis of the potential optative with $\hat{\eta}$ and $\alpha \rho \alpha$ and without them (Sections 7 and 8). Section 9 presents the conclusions and avenues for further research.

\section{Previous literature on the potential optative and particles}

There are quite a few methodological dangers in using our standard grammars for the synchronic linguistic analysis of moods. Most analyses in these grammars propose a general characterization of the potential optative's value that covers an enormous diachronic period of Greek. For example, Kühner-Gerth's characterization of the potential optative is intended to hold for Homeric Greek, Classical Greek and post-classical Greek, apart from some changes that are discussed. ${ }^{7}$ To account for differences in value, these grammars list uses. Although these uses provide insights into the pragmatic functions of utterances with the potential optative, they obscure the relationship between the semantics and the pragmatics of the potential optative itself. Such uses do not specify which semantic meaning as opposed to pragmatic meaning the optative mood form codes as potential optative..$^{8}$ Needless to say, not observing the (later) distinction between semantics and pragmatics is not something that can really be held against traditional grammars such as Kühner-Gerth's, but we should be duly aware of their different approach. Another drawback of these grammars is that they still thought of modality and mood as fundamentally subjective categories, ${ }^{9}$ a view which has been retained until now. ${ }^{10}$

$7 \quad$ Also, Kühner \& Gerth (1904: 231) and Goodwin (1867: 291) treat post-Homeric poetry and Homer under the same header as poetry, as opposed to prose, thus generalizing over genre instead of diachronically different types of Greek.

8 The description inspired by Functional Grammar by Revuelta Puigdollers (2005) offers a promising start, as it more systematically separates semantic from pragmatic values with the moods.

$9 \quad$ E.g. Kühner \& Gerth (1904: 201). Schwyzer \& Debrunner (1950: 303) are slightly more nuanced.

10 See the EAGLL chapter on Mood and Modality by Ruiz Yamuza (2014: 456), who contends that any expression of modality seems to be subjective. A different but related approach is 
This paper, however, will follow recent general linguistic studies that have falsified this assumption. ${ }^{11}$

As for particles, the grammars have so far only dealt with explaining the problematic distribution of the particle $\alpha^{\prime} \nu$ with the potential optative. Although there are Classical Greek potential optatives without $\alpha^{\prime} \nu$ in metrically and non-metrically conditioned texts, ${ }^{12}$ Kühner \& Gerth claim that in Attic, $\ddot{\alpha} \nu$ is as a rule rightly added to texts by editors when a main clause optative with a potential meaning lacks $\alpha$ $\nu$. Still, we know that non-Attic Greek did not observe this rule (Slotty 1915: 83-84), leaving the precise function of $\alpha$ controversial. ${ }^{13}$ Recently, Zingg (2017) has argued that $\alpha \dot{\alpha} v$ was added to the future in Classical Greek, ${ }^{14}$ which in my view makes it worth considering that the particle has multiple functions dependent on the mood it occurs with. ${ }^{15}$ After all, $\alpha 2 v$ is said to be obligatory with the counterfactual indicative in the main clause (Rijksbaron 2006: 7) whereas it is not fully obligatory with the potential optative in the main clause, pointing to a difference in status for both combinations.

More recently, Ruiz Yamuza (2000) has attempted to describe the combina-

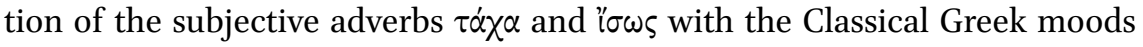
(including the optative) within a Functional Grammar framework. While I share her view that the adverbs can occur with both subjective modalities and objective modalities, I have several objections to the way she develops her argument. First of all, in her sketch of the Classical Greek mood system she claims that the potential optative expresses both possibility and probability, instead of possibility only (Ruiz Yamuza 20oo: 238) as is more generally accepted (Crespo 1992: 296-299; Allan 2013a: 31). This classification confusingly aligns the potential optative with the future indicative, which is, in its use for predic-

Allan (2013a:10), who interprets the Ancient Greek moods as so-called grounding predications, speaker-oriented modal expressions that locate state affairs relative to the speaker and hearer and their spheres of knowledge.

11 Especially Narrog (2012: 13-45). He critically discusses almost all takes on subjectivity that have been implemented in linguistics and why it should be kept separate from modality and mood.

12 Oddly enough, Kühner \& Gerth (1904: 225, 231) suggest a difference in meaning for the potential without versus with $\ddot{\alpha} v$.

13 E.g., Smyth (1920: 398), who states: "ळँv limits the meaning of the moods". Others suggest that $\alpha$ 'v potentializes the optative, such as Goodwin (1867: 77-78) and Kühner \& Gerth (1904: 245), or that it is a stylistic feature (Bers 1984: 117-142).

14 Cf. Crespo (1984), who showed how editors have, in a structural fashion, removed $\ddot{\alpha}$ from its occurrence with the infinitive even after verbs of saying and thinking.

15 Perhaps the different functions all in some way relate to the more general characterizations that have been offered in the literature to cover all its uses, e.g., Gerö (2000) or Allan (2015). 
tions, epistemically subjective in nature and different in use (Allan 2017b: 53). Secondly, she argues - wrongly, in my view - that every combination of "these modality adverbs and the optative mood, future tense or the subjunctive mood are harmonic combinations, since both the adverbs and these moods express the same grade of factuality: either probability or possibility" (Ruiz Yamuza 2000: 242; also 2014: 457). Harmonic combinations of epistemic judgments can, however, only be the case when the two modal elements share the same modal strength (Hengeveld \& Mackenzie 2008: 174; Lyons 1977: 807). As I argue later in this paper, the potential optative is non-harmonic with subjective markers because it has a different modal strength as non-subjective modality. Thirdly, she applied tests that had been used in Functional Grammar at the time to distinguish between subjective and objective modality types, but those tests have since been abandoned. ${ }^{16}$ Naturally, she cannot be blamed for this, but it does bear on the validity of her findings, as, for example, alleged oddities in behaviour are not, in fact, oddities. ${ }^{17}$

After her, Denizot (2011) has shown how a speech-act-theoretic approach provides insights for the description of the pragmatic functions of moods (including the optative). Nevertheless, due to her focus on the pragmatic side of moods, I do not agree with her semantic characterization of the potential optative, that is, as an instance of so-called alethic modality (Denizot 2011: 409419). The category of alethic modality originated from modal logic and is used to refer to what is marked as logically true in the world. She took this from what seems to me a quite outdated tripartition of the modal domain in alethic, deontic and epistemic modality (Denizot 2011: 31, from Gardes-Tamine 1987). First of all, epistemic modality is defined there as inherently subjective, a position that I argue against in Section 3. Second, it had already been suggested that the notion of alethic modality creates a false linguistic distinction since "there is no distinction between (...) what is logically true and what the speaker believes, as a matter of fact, to be true" (Palmer 1986:11). ${ }^{18}$ Third, I think that alethic modality should only be considered as a label if there are many strong arguments to support it, because alethic modality is rarely grammatically coded (Narrog 2012: 6 ), and because in linguistic analysis the notion is "hardly ever used" (Nuyts 2006: 9).

The most recent proposal for the potential optative in Classical Greek has been Drummen (2013), who adopted a Construction Grammar approach to pin-

\footnotetext{
16 Cf. Narrog (2012: 13-45).

17 For example, she gives an instance of " $\sigma \omega \varsigma$ in focus to show that it does not meet an older requirement from Functional Grammar of focus status for higher layer operators, but this test has already been abandoned.

18 This book is mentioned in her bibliography.
} 
point the relationship between the many different interpretations of the potential optative. Unfortunately, Construction Grammar assumes no difference between semantic and pragmatic meaning in their classification of constructions (Drummen 2013: 72-73). As a result, Drummen's classification defines a set of uses (much like the grammars before her) which mix semantics and pragmatics, although admittedly with specific linguistic characteristics per use. She claims that the link between all uses are due to both form and meaning. The formal part consists of the optative mood and the particle $\ddot{\alpha} v$, even though instances without $\alpha \dot{\alpha}$ occur in her corpus, as well as in Classical Greek in general. The supposed meaning link is "epistemic possibility" since the potential optative in all its related constructions expresses that it "is possible (according to the speaker) that the state of affairs obtains" (Drummen 2013: 38; my italics). Besides theoretical objections to her approach already mentioned above, I would like to discuss two problems in more detail, because they concern relevant aspects of the potential optative that feature in the remainder of this article. First of all, the attempt to identify her "epistemic possibility" as the shared meaning across all constructions is not carried out consistently. On the one hand, she also claims that the combination of the potential optative with $\tau \dot{\alpha} \chi \alpha \alpha$, " $\sigma \omega \varsigma$ and $\pi \circ v$ is harmonic (Drummen 2013: 77). As discussed above, these elements, do not have the same strength and subjectivity, making them nonharmonic. ${ }^{19}$ On the other hand, this explanation conflicts with her proposal for the shared meaning of (subjective) epistemic possibility because she claims that the epistemic value of the potential optative "has scope over the whole proposition" (Drummen 2013: 74). As I argue below, proposition scope is a trait which is confined to proper subjective epistemic modalities and is therefore not a trait possessed by the non-subjective epistemic modality of the potential optative.

My second point of disagreement relates to her claim that the potential optative can have the epistemic possibility meaning with proposition scope at the same time as a non-epistemic participant-oriented possibility meaning with non-propositional scope. ${ }^{20} \mathrm{In}$ my view, this is unattractive from a theoretical

\footnotetext{
19 The particle $\pi \circ v$, in my view, is not subjective but modifies an illocution, as suggested by Allan (2015: 14).

20 Drummen (2013: 75; and in-depth at 8o-89). 'Participant-oriented possibilities' is a term she herself coined to encompass "inherent abilities (participant-internal abilities) as well as circumstantial conditions (participant-external possibilities) enabling or disabling a participant to engage in a state of affairs." Note that Drummen here reworks the idea promoted by Willmott (2007) for the Homeric Greek potential optative having a dynamic modal meaning for Classical Greek (Drummen 2013: 70).
} 
point of view because two types of modality do not exist in one marker with different scopes at the same usage time. Rather, I suggest that such participantoriented nuances are the result of contextual inference and not part of the semantics of the optative, as becomes clear from the use of capacity verbs in

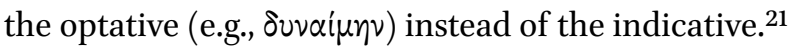

To summarize, the lack of a clear distinction between the coded semantic and pragmatic meaning of the potential optative exists throughout the literature. The conceptual assimilation of subjectivity with moods and modality in our standard grammars has been taken over in recent literature, although recent proposals in general linguistics (especially Narrog 2012: 23-45), which I discuss in the next section, rightly reject this idea. The particles occurring with the potential optative still have many insights to offer, since previous attempts have in my view not been successful.

\section{3}

Epistemic modality versus subjectivity

In this section, I demonstrate why epistemic modality should be kept separate from subjectivity. Epistemic modality is a semantic category which should be defined as concerning "an indication of the estimation, typically, but not necessarily, by the speaker, of the chances that the state of affairs expressed in the clause applies in the world" (Nuyts 2006: 6, my italics). ${ }^{22}$ In other words, epistemic modality is applicable "when the degree of compatibility (or overlap) between the modal world and the factual world is at stake" (Declerck 2011:33).

Linguistic subjectivity ought rather to be measured through a set of factors with performativity as its primary quality. Performative expressions qualify "a proposition with respect to the current speech situation (including speaker and hearer)", whereas non-qualifying expressions are seen as descriptive (Narrog 2012: 42). ${ }^{23}$ Subjectivity cannot be associated in a strictly categorical fashion with a specific word class (such as adverbs ${ }^{24}$ ), since linguistic items that

21 Ruiz Yamuza (2014: 456) discussed this idea as suggested by Willmott (2007) for Homeric Greek and suggests this nuance is actually "context-based inference".

22 See also Narrog 2012: 8. Both Nuyts (2006) and Narrog (2012) deliberately steer away from the trap of defining epistemic modality solely in subjective epistemic terms, as do Bybee et al. (1994: 179) and Allan (2013a: 4).

23 Narrog's definition closely mirrors the formulation by its inventor, Nuyts (2001: 39) but does not suggest an association with epistemic forms only. Also, it allows for a more gradual view as a scale of performativity by not suggesting that performative expressions always express full commitment by the speaker (as for example Nuyts 2002: 446).

For Ancient Greek adverbs, see Ruiz Yamuza (2006) and Dik (2014). 
express a speaker's subjective attitude toward the state of affairs belong to different word classes. ${ }^{25}$ Moreover, the same linguistic item can express subjective meanings as well as non-subjective meanings depending on the context, as witnessed by the possibility of a non-subjective deontic and a subjective epistemic meaning for must. ${ }^{26}$

Besides the core notion of speaker-oriented commitment, subjectivity has an important second dimension of evidence accessibility. That dimension concerns the question of whether the expression "in a specific context expresses a judgment which is based on evidence and/or values that are only accessible to the speaker" (Narrog 2012: 43). By contrast, the expression of a judgment "based on evidence and/or values that are accessible or shared by a community of speakers" is less subjective. ${ }^{27}$ In Classical Greek, for example, a statement which is marked by inferential $\ddot{\alpha} \rho \alpha$ indicates that the speaker bases the validity of his/her statement on his/her subjective inference (Allan 2017b). Finally, the current approach to subjectivity asks for close examination of the context, the place that can show us how a subjective statement relates to currently held views and knowledge.

Distinguishing among different types of epistemic modality comes down to the scope of the modal expression. In contrast to non-subjective epistemic modalities, subjective epistemic modalities have scope over a proposition, such as epistemic 'must' in the sentence John MUST have forgotten the meeting. ${ }^{28}$ Here must expresses the speaker's commitment to the idea that the modal and factual world overlap, that is, that the state of affairs that John has forgotten the meeting is the case. With a non-subjective epistemic modality such as may in He MAY have forgotten, the speaker's commitment is absent, and may does not have propositional scope as it is part of the state of affairs expressed. As a result, speakers can make the conscious choice to add items with propositional scope to may, as in CERTAINLY, he MAY have forgotten. Components with propositional scope may be expressed not only by a modal expression but

25 See Narrog (2012: 31) and de Smet \& Verstraete (2006).

26 Admittedly, there is a diachronic trend that more subjective meanings are the more grammaticalized ones, since grammaticalization and subjectification tend to go hand in hand. For this phenomenon, see Allan (2013a) and the references cited there.

27 Narrog's definition of this dimension is inspired by Nuyts' frequent definitions of 'subjectivity' as an evidential dimension (i.e., the degree to which the speaker is responsible for the evidence of the assessment).

28 Several theories of grammar acknowledge a non-subjective type of epistemic modality, such as Functional Grammar by Dik (1997) and Functional Discourse Grammar by Hengeveld \& Mackenzie (2008), which have inspired this article. For an overview of functional theories, see Butler (2003). 
also by subjective adverbs ( $\tau \dot{\alpha} \chi \alpha$ and $\left.{ }^{\prime} \sigma \omega \varsigma\right)$ and particles ( $\hat{\eta}$ and $\left.\alpha{ }^{\prime} \alpha\right) .{ }^{29}$ In such combinations, the expression has an identifiable non-subjective and subjective component whose use is contextually determined. When a subjective epistemic modality occurs with $\hat{\eta}$ or $\alpha$ p $\alpha$, both are harmonic because they express the same modal strength. Consequently, they strengthen each other much like He TRULY MUST bejoking. However, when a non-subjective modality combines with $\hat{\eta}$ or $\alpha$ p $\alpha$, they are non-harmonic, which makes the subjective particles scope over them much like He CERTAINLY MAY have forgotten. This difference becomes relevant to understanding the low frequency of combination of the non-subjective potential optative with subjective particles.

\section{Alternative approach to the semantics of the potential optative}

As I now argue, the combinations of the Classical Greek potential optative when combined with $\hat{\eta}$ and/or $\ddot{\alpha} \alpha$ make up a complex combination in the same way that may and certainly do. The non-subjective epistemic character of the potential optative is that it presents a judgement as interpersonally accessible to the addressee(s), that is, epistemically shared between the speaker and addressee(s). ${ }^{30}$ For this proposal, I adduce four types of support in the following sections. First, I discuss the contextual semantics of the potential optative in examples to clarify my proposal. Second, I show that the low frequency of combination of the potential optative with the subjective particles supports this proposal. Third, I apply linguistic tests for subjectivity to the potential optative that point out that it is semantically non-subjective. Finally, an analysis of contrastive contexts with and without $\hat{\eta}$ and/or $\alpha$ p $\alpha$ demonstrates that $\hat{\eta}$ and/or $\ddot{\alpha} \rho \alpha$ are added as a subjective component to the non-subjective potential optative for social or rhetorical reasons. Let us first consider some examples of the potential optative on its own.

In the following example, Calonice presents her judgement as something that everyone present knows is possible, since it concerns something that

29 The classification of the Ancient Greek particles by Allan 2015 distinguishes between grammatical expressions (operators) such as modalities, tense or particles, and lexical expressions such as adverbs (modifiers).

30 This conception of the epistemic value of the optative in Classical Greek has the benefit of relating to the value of the optative in reported speech proposed in the literature. As has been discussed by van Rooy (2016: 34-37) and several others before him, the optative in reported speech also marks lack of speaker commitment: "as far as it signals that the speaker/narrator in the hic et nunc moment of speaking/narrating does not commit himself to the information expressed by others or by himself in past contexts." 
everybody knows on the basis of their general knowledge of the world. Thus, the potential optative expresses that the conversational participants know that it is possible that such a big wine jug makes merry, instead of Calonice stating that she personally strongly believes that the wine jug will make merry.

(2) Myrrhine:

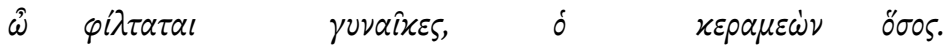

voc dearest.NOM.PL ladies.NOM.PL the.NOM jug.NOM.SG what.Q

Calonice:

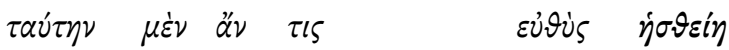

this.ACC PTC PTC someone.NOM at.once become.happy.OPT.AOR.3SG $\lambda \alpha \beta \omega \dot{\nu .}$

touch.PTCP.AOR.NOM.SG

Myrrhine: Dearest ladies, what a jumbo jug!

Calonice: Just touching this would make a person merry! (Ar. Lys. 20o201)

Because the potential optative is used to present a judgment as epistemically accessible to speaker and hearer, it shows a preference to occur in generalizing statements which the hearers are presumed to be aware of. For example, of the 340 uses of indefinite $\tau \iota$ in Aristophanes in main and subordinate clauses, $5^{\circ}$ occurrences have the potential optative, whereas it combines with the future indicative only 19 times to make indefinite future predictions. Similarly, in the next example the optative in the question does not mark subjective commitment to the state of affairs that women do something, but rather asks about a presupposed possibility. Lysistrata in the preceding sentence made this possibility interpersonally accessible by saying that the women are able to save Greece.

(3) Lysistrata:

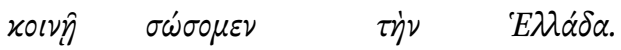

together rescue.1PL.FUT the.ACC Hellas.ACC.SG

Calonice:

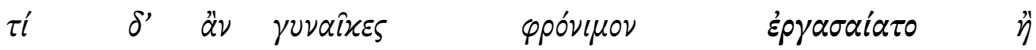

what.Q PTC PTC women.NOM.PL prudent.ACC.SG do.OPT.AOR.3SG or $\lambda \alpha \mu \pi \rho o ́ v ;$ ai $\quad \alpha a \vartheta \eta_{\mu} \mu \vartheta^{\prime} \quad \dot{\varepsilon} \xi \eta \nu \vartheta l \sigma \mu \varepsilon \dot{\nu} \alpha l$, bright.ACC REL.NOM.PL sit.PRS.1PL look.pretty.PTCP.PRS.NOM.PL 


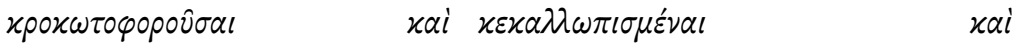

wear.saffron.PTCP.NOM.PL and wear.make-up.PTCP.PRF.NOM.PL and

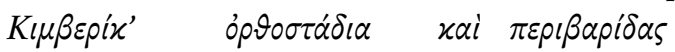

Cimberic.ACC gown.ACC.PL. and pleasure-boat.slippers.ACC.PL

Lysistrata: together we'll be able to rescue Greece!

Calonice: But what would mere women do that's intelligent or illustrious? We sit around the house looking pretty, wearing saffron dresses, and make-up, and Cimberic gowns, and pleasureboat slippers. (Ar. Lys. 41-45)

The non-subjective epistemic semantic characterization is also more attractive for the use of the potential optative in emphatic refusals below, provided that the semantic and the pragmatic force of the potential optative are kept separate.

(4) Lysistrata:

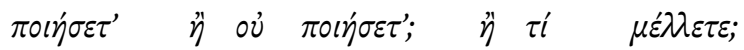

do.FUT.2PL or not do.FUT.2PL or why.Q delay.PRS.2PL

Calonice:

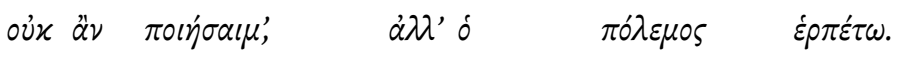

not PTC do.OPT.AOR.1SG but the.NOM war.NOM.SG drag.on.IMP.3SG

Lysistrata Will you do it or not? What are you waiting for?

Calonice Count me out; let the war drag on (Ar. Lys. 127-129)

Later on in the play the women reject Lysistrata's proposal to perform a sex strike. The choice for the potential optative by Calonice is, in my view, made in order to present the impossibility of Calonice's participation more strongly, that is, as unnegotiable. In my view, its semantic value should be paraphrased as: 'as you (and I) know, it is not possible that I would do that'. The reason that the interlocutors know that especially Calonice would not be able to give that up is that she has been complaining from line 102 onwards about how she misses her husband and sex more in general, since lovers have also abandoned her. With this, the other women agreed. Thus, presenting something as semantically impossible (as everybody knows) is rhetorically strong and contributes to the strong pragmatic refusal value of the utterance as a whole here. 
The comparative frequency of $\hat{\eta}$ and $\alpha$ p $\alpha$ with specific mood types also argues against an explanation of the potential optative as subjective epistemic, because the potential optative occurs markedly less often with these subjective particles than other more subjective moods do. After all, if the potential optative actually were subjective epistemic, an affinity in combination with these subjective particles would be expected. However, subjective uses of the future in harmonic combinations with subjective particles are considerably more frequent than the non-harmonic combinations of the non-subjective potential optative with subjective particles. To provide a diverse sample of the frequency of combination, I measured the occurrence of the optative combinations in different genres, in particular comedy (Aristophanes), tragedy (Euripides) and philosophical dialogue (Plato). ${ }^{31}$

As shown in the table, the subjective particles in general strongly prefer to occur with the indicative mood over the potential optative in every writer and occur about twice as often with the future indicative in a subjective use. Also, the data on the future indicative for the Platonic tests is even somewhat skewed by the fact that the future indicative in Plato had acquired a further subjective use (called "logical-inferential" by Bakker 2002), which made combination with these subjective particles less necessary. ${ }^{32}$

To underline the fact that combinations of the potential optative with the subjective particles are quite a marked option, I compared the combinations with $\hat{\eta}$ and $\alpha \rho \alpha$ to the frequency of non-combined potential optatives. In five plays of Aristophanes the potential optative occurs 106 times in total, whereas it combines with $\hat{\eta} / \alpha{ }^{\prime} \alpha \alpha$ only once. ${ }^{33}$ Compared to an average of 1431.8 lines per comedy, ${ }^{34}$ the potential optative thus occurs rather sparingly, as non-combined potential optatives occur in $1.48 \%$ of the lines in a play compared to $0.01 \%$ for the combination with $\hat{\eta}$ and $\ddot{\alpha} \rho \alpha$. This makes it highly unlikely that the potential

31 I distinguish between the non-future indicative and the future indicative because most of the future indicative's uses are inherently subjective, as when used with these particles (Allan 2017b: 51-57). The same preference applies to collocation with subjectively

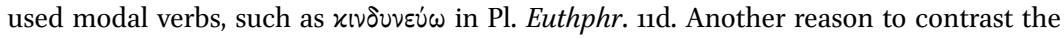
frequency with the indicatives is that the particles occur only extremely rarely with the subjunctive, that is, $\hat{\eta}$ before a dubitative subjunctive or a subordinate clause and $\ddot{\alpha} \rho(\alpha)$ in conditional or subordinate clauses with a subjunctive or with an adhortative subjunctive. See, respectively, E. Or. 787, Pl. Ap. 37b, Pl. R. 389d, Hp. Ma. 239e and Tht. 205e.

32 See further Allan (2017b: 56-57).

33 Based on Ar. Ra., Lys., Ec., Av. and Pax.

34 This average is based on the following numbers: $1533+1321+1183+1357+1765=7159 / 5=1431,8$. 
TABLE 1 Collocation of $\hat{\eta}$ and $\alpha$ p $\alpha$ with moods ${ }^{\mathbf{a}}$

Mood

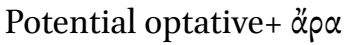

Future indicative $+\not \alpha \rho \alpha$

Non-future indicative+ $\alpha$ p $\alpha$

Potential optative without $\hat{\eta} / \alpha \ddot{\rho} \alpha$

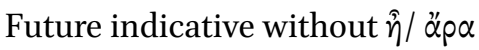

Potential optative $+\hat{\eta}$

Future indicative $+\hat{\eta}$

Non-future indicative $+\hat{\eta}$
Aristophanes Euripides Plato Total

$\begin{array}{rrrr}3 & 2 & 79 & 83 \\ 32 & 17 & 104 & 153 \\ 91 & 86 & 544 & 721 \\ 662 & - & - & - \\ 1676 & 2112 & 3593 & 7586 \\ 2 & 8 & 17 & 27 \\ 13 & 19 & 18 & 50 \\ 41 & 73 & 81 & 195\end{array}$

a Texts transmitted as fragments and Plato's spurious works are left out. Please note that the number of total potential optatives was counted by hand, whereas the total of future indicatives without $\hat{\eta}$ and $\alpha \rho \alpha$ was calculated by subtracting the total of combinations of the future indicative with $\hat{\eta}$ and $\ddot{\alpha} \rho \alpha$ from the total of future indicatives found in a Perseus search under Philologic.

optative has a subjective epistemic semantics. Rather, the numbers suggest that the potential optative has non-subjective epistemic semantics, which explains its lack of affinity in combination with subjective particles such as $\hat{\eta}$ and $\alpha$ p $\alpha$.

\section{$6 \quad$ Linguistic tests for subjectivity}

Now I will apply tests for the subjectivity of modal markers to the potential optative. The following formal and distributional properties of linguistic items make a non-subjective (descriptive) reading of a marker of epistemic modality more likely: ${ }^{35}$

1. The possibility of past marking

2. The possibility of negation

3. The possibility of subjecting the modalized clause to interrogation

4. The possibility of using it in the protasis of conditionals

5. The scopal relationship in double modal marking

35 These tests come from Lyons (1977: 799) and Hengeveld (1988: 236-240) and are critically discussed by Narrog (2012: 31-39). I rearranged their original order to the order of discussion and left out the test of 'questioning the source of the information', which allegedly is infelicitous with subjective modal markers because of the critiques mentioned in Narrog (2012: 36). 
The first property points to the fact that past marking on the modal item "removes the judgment deictically from the speaker's present point of view, since the time of the judgment is explicitly associated with a point in time different from the time of speech, and the past point of view does not necessarily coincide with the present one". ${ }^{36}$ The judgment in the following example thus is not made about the current speech situation but it is more objectively made in the past.

(5) Given that nobody had left the ship, the murderer still had to be around.

The Classical Greek optative lacks such a past temporal value. However, the potential optative does have a linguistic association with the past in that it is licensed after past indicatives in the main clause (Rijksbaron 2006: $5^{-54)}$ in many types of subordinate clauses, for example, of reported speech, indirect questions or causal clauses. ${ }^{37} \mathrm{~A}$ suggestion that might be relevant from a diachronic perspective is that the secondary endings of the optative imply epistemic distance (Allan 2013a: 41), which could perhaps point to the optative's descriptiveness.

In a similar way, immediate negation of a modal marker "indicates a distance between the judgment expressed in the modal marker, and the actual speaker's judgment at the time of speech" (Narrog 2012:34). ${ }^{38}$ In other words, if both tense and negation can modify a modal marker, it is likely that this marker has a higher degree of event orientation, meaning that the modal value marks conditions on the event instead of the speaker's evaluation of that event (Narrog 2012: 34, 51). Lanski (2013) has convincingly shown that the negation with a potential optative negates the potential value (as in the paraphrase of example 4) which therefore points to a higher level of descriptiveness for the potential optative.

The third testing property is based on the fact that it is difficult to combine questioning with a subjective assessment, as below: ${ }^{39}$

$36 \quad$ Narrog (2012: 32$)$ gives example 5 and some additional examples from Japanese.

37 Relatedly, the optative in oblique sentences in Classical Greek can be marked by relative tense by the future pointing to a more descriptive value for the optative mood. For the future optative, see Martínez Vázquez (1995) and de la Villa (2017).

38 De Haan (2006: $5^{2-56)}$ notes that the negation criterion can be difficult to apply since every language has widely different idiosyncratic rules for negation, and negation markers are sometimes selected for constructions without clear reasons via suppletion.

39 It is, however, not impossible, since we see $\hat{\eta}$ and $\ddot{\alpha} \alpha \alpha$ in questions with the potential optative coding subjectivity. 
(6) A: Tom must have arrived.

B: *Must he? ${ }^{40}$

The insertion of a subjective modal item in a question can make it lose its subjective value and now reflects a non-subjective viewpoint, echoing the viewpoint of speaker A. ${ }^{41}$ We know that the potential optative actually can be used without limitations in questions. ${ }^{42}$

The fourth property states that the use in a conditional is denied to a subjective marker, since it cannot present a performative assessment because the conditional is functionally opposed to it as a marker of absence of commitment (Verstraete 2004: 251). The use in a conditional would have somewhat infelicitously questioned a marker of commitment, as in the following example. The subjective marker consequently becomes echoic:

(7) A: In my view Socrates must be the wisest man alive.

$\mathrm{B}$ : If he must be the wisest man alive, why are they going to kill him then?

'Must' now echoes the subjective assessment by speaker A and cannot belong to speaker B. The potential optative has no problem occurring in conditionals and is probably more descriptive on the basis of this property, because it is said that in conditionals it "presents the realization of the condition as just possible and no more than that" (Wakker 2013; Ruijgh 1971). To sum up, the first four tests for subjectivity point out that the potential optative is not subjective epistemic in value. As will become clear in the following sections, the fifth test demonstrates the scope of $\hat{\eta} / \alpha \ddot{p} \alpha$ over the non-subjective potential optative. In other words, the test of double modal marking will demonstrate that the combinations of the potential optative with $\hat{\eta}$ and $\alpha$ p $\alpha$ are non-harmonic, since the potential optative of a non-subjective modal strength.

\section{The combination with $\hat{\eta}$}

I see $\hat{\eta}$ as a strongly speaker-oriented particle expressing "a high degree of speaker commitment",43 marking "personal commitment of the speaker to the

\footnotetext{
$40 \quad \operatorname{Narrog}(2012: 35)$.

41 For this echoing phenomenon, see Verstraete (2004: 249-250) and Narrog (2012: 35).

42 Cf. Rijksbaron (2006: 5-9) and e.g., E. Ba. 945.

43 Although I do agree with Bonifazi et al. (2016: 3.2.2) that the particle $\hat{\eta}$ involves speaker involvement, I would not say that its core value $\hat{\eta}$ is expressive, but rather epistemic.
} 
validity of the utterance". ${ }^{44}$ In Allan's classification, this particle in my view rightly belongs to the layer of propositional content on the semantic (representational) level. Evidence for this classification is that it scopes under questions, whereas (interactional) particles on the pragmatic (interpersonal) level do not. ${ }^{45}$ I argue that the particle is added to the potential optative when a speaker wants to mark his/her commitment to an accessible possibility for rhetorical or social reasons, as in the following example:

(8) Strepsiades:

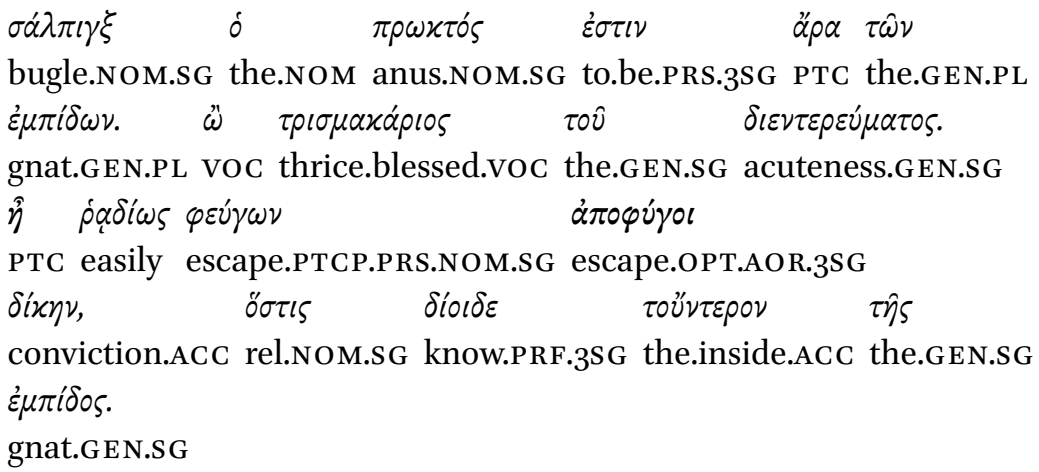

Strepsiades: So the gnat's arsehole turns out to be a bugle. Thrice happy man, for such penetrating enterology! As a defendant he'd certainly escape conviction, since he knows the gnat's gut inside out. ${ }^{46}$ (Ar. Nu. $165^{-168)}$

Strepsiades uses the combination to acknowledge his personal commitment $(\hat{\eta})$ to the contextually given possibility that Socrates would escape conviction ( $\dot{\alpha} \pi \circ \dot{v}$ yol). The explanation for his stance-taking lies in the previous context.

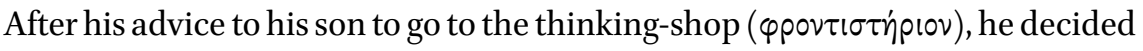
that he also wanted to acquire some knowledge himself. The first thing that the

44 Cuypers (2005: 50) and Denniston (1954: 279-288). This view diverges slightly from the one presented by Sicking \& Van Ophuijsen (1993) and Wakker (1997: 213), who define the particle in opposition to $\mu$ ' $\nu$. For $\mu$ 'v $v$, I agree instead with Thijs (2017).

45 Cf. Wakker (1997: 218-223). And see Allan (2015: 8) for an example.

46 Here I changed the translation with 'he'd certainly be able to' to 'he'd certainly' because, as I mentioned, I do not want to create the impression that I think that the Classical Greek potential optative has a (non-epistemic) dynamic modal meaning, contrary to Drummen (2013: 8o-89), in that it would express a participant's capacity. Rather, the potential optative only has an epistemic semantics. 
pupil in the thinking-shop shares with him is some secret knowledge received from Socrates who used wax to measure how many feet gnats use to jump from one place to another after biting someone. Importantly, the pupil qualifies Socrates' solution as very clever $\left(\delta \varepsilon \xi \xi_{1}^{\prime} \tau \alpha \tau \alpha, 1.148\right)$ and Strepsiades completely agrees praising Socrates' subtlety of thought ( $\hat{\omega} Z \varepsilon \hat{\imath} \beta \alpha \sigma i \lambda \varepsilon \hat{\nu} \tau \hat{\eta} \varsigma \lambda \varepsilon \pi \tau o ́ \tau \eta \tau ం \varsigma ~ \tau \hat{\omega} \nu$ $\varphi p \varepsilon v \hat{\omega} v$, l. 153). This way, Socrates' cleverness is made accessible to the conversational participants. ${ }^{47}$ When the pupil thereafter speaks of another clever solution by Socrates, Strepsiades reacts, in line with his previous admiration of the nonsense knowledge that he had been given, by saying that that knowledge is the knowledge to have if one wants to escape conviction (see the following relative clause). Thus, Strepsiades personally believes ( $\hat{\eta})$ that Socrates' escape may be assumed by the addressee as possible.

The particle $\hat{\eta}$ occurs nearly as often in declarative sentences as in interrogative sentences. In questions, $\hat{\eta}$ is used by speakers to subjectively commit oneself ${ }^{48}$ to a possibility that is already interpersonally given but about which the speaker suggestively asks if the addressee thinks that this commitment is right. After cornering Socrates and Glaucon at the start of the Republic, Polemarchus threatens them that they can only leave if they outdo them.

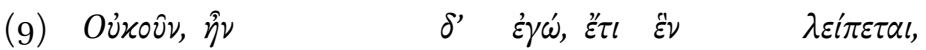
PTC to.say.IMPF.1SG PTC I still one.NOM remain.PRS.3SG tó $\quad \dot{\eta} \nu \pi \varepsilon i \sigma \omega \mu \varepsilon \nu$ i $\mu \hat{\alpha} s$ is $\chi \rho \dot{\eta}$ the.NOM.SG if persuade.SUBJ.AOR.1PL you.ACC that should.PRS.3SG $\dot{\eta} \mu \hat{\alpha} s \quad \dot{a} \varphi \varepsilon \hat{i v a l ;}$ we.ACC let.go.INF.AOR

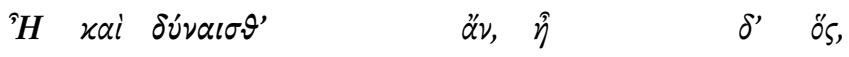

PTC and be.able.opt.PRs.2PL PTC say.IMPF.3SG PTC he.NOM $\pi \varepsilon \hat{\sigma} \sigma a l \quad \mu \dot{\eta} \quad \dot{\alpha} \times o v$ ovtas; persuade.INF.AOR not listen.PTCP.PRS.ACC.PL

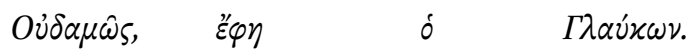
Certainly.not say.IMPF.3SG the.NOM Glaucon

47 It is well conceivable that Socrates' cleverness was proverbial, communally shared knowledge, but for the sake of explanation I leave this matter aside.

48 Following Hengeveld \& Mackenzie (2008: 71), I also distinguish a propositional layer in interrogative sentences. 
Polymarchus: 'Yes, but don't we still have the alternative,' I said, 'to see if we can persuade you to let us go?'

'Would you really have any success,' he said, 'in persuading those who don't listen?'

'No, we certainly wouldn't,' said Glaucon. (Pl. R. 327c)

The alternative that Socrates tries to offer is thrown off the table by what Polemarchus' statement with the optative combination implies. The question with the optative asks about the interpersonally accessible knowledge that people who do not listen cannot be persuaded, which counters Socrates' hope that persuading them would free him and Glaucon. The subjective particle $\hat{\eta}$ is what makes the question persuasive. The full contextual value of the question could be paraphrased hierarchically as 'I ask (interrogative sentence type) whether I may really ( $\hat{)}$ ) think that you would have any success (potential optative)'. Thus, the subjectivity of $\hat{\eta}$ concerns the given possibility that Socrates and Glaucon would have a way out of their captivity.

Let us next consider contrastive contexts with and without $\hat{\eta}$. In his quest to revenge his father's death, Orestes investigates, whilst unrecognized by Electra, whether she is willing to kill her mother. Therefore he asked her how Orestes would kill his father's killers if he came home (in line 274). Importantly, the 'how' question presupposes that he would, showing that both are aware of the possibility that Orestes would kill his father's killers.

(10) Orestes:

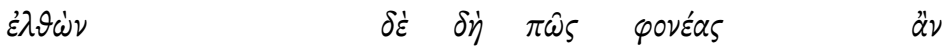

come.PTCP.AOR.NOM.SG PTC PTC how.Q murderers.ACC.PL PTC

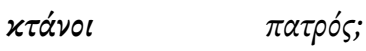

kill.opt.AOR.3sG father.GEN.SG

Electra:

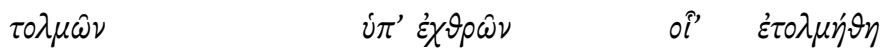

dare.PTCP.PRS.NOM.SG by enemies.GEN.PL what endure.AOR.3SG

$\dagger \pi \alpha \tau \dot{p} \rho t$.

father.NOM.SG

Orestes:

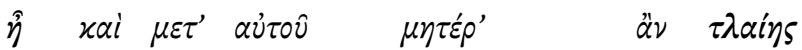

PTC also with he.GEN.SG mother.ACC.SG PTC dare.OPT.AOR.2sG

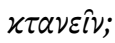

Kill.INF 
Electra:

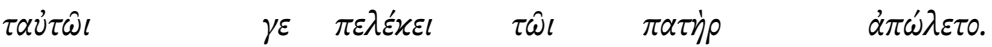

the.same.DAT.SG PTC axe.DAT.SG the.DAT father.NOM.SG die.3SG.AOR

Orestes: But if he does come, how would he kill his father's murderers?

Electra: By showing the same boldness his enemies once showed.

Orestes: Surely would you also have the hardihood to kill your mother with his help?

Electra: Yes, with the same ax with which my father met his death! (E. El. 274-277)

The subsequent potential optative enquires about Electra's tolerance of the presupposed possibility that Orestes would kill their father's killers when he comes ( $\dot{\varepsilon} \lambda \theta \dot{\omega} \nu \delta \dot{\varepsilon} \delta \dot{\eta})$. By contrast, Orestes in this question specifies his subjective belief (with $\hat{\eta}$ ) that Electra would also have the strength to kill her father's murderers, a given possibility because of her previous expressions of hatred against the killers of her father. This subtle rhetorical difference in subjectivity in turn draws out a commitment formulation by Electra in the next sentence.

Also in a contrastive context with examples slightly further apart from one another, the subtle difference in subjectivity becomes clear from the use. In example 11, Socrates has just responded to Phaedrus' promise to recount his thought-provoking meeting with the writer Lysias by asking a rhetorical question, a question which implied that hearing the conversation was most important.

(11) Phaedrus:

$\pi p o ́ \alpha \gamma \varepsilon \quad \delta \dot{\eta}$.

lead.on.IMP.2SG PTC

Socrates:

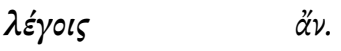

speak.OPT.PRS.2SG PTC

Phaedrus:

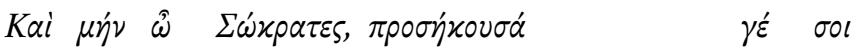

PTC PTC voc Socrates be.fitting.PTCP.PRS.NOM PTC you.DAT.SG

$\dot{\eta} \quad \dot{\eta} x o \dot{\eta}$.

the.NOM.SG hearing.NOM.SG 
Socrates:

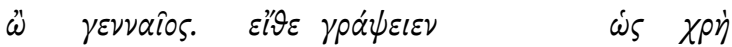

vOc noble.voc PTC write.opt.AOR.3SG that should.PRS.3SG

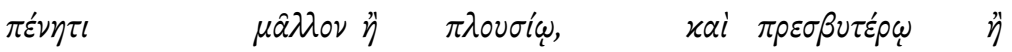
the.poor.DAT.SG rather than the.rich.DAT.SG and the.old.DAT.SG than

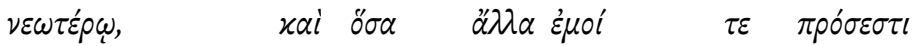
the.young.DAT.sG and what.Q but me.DAT.SG PTC belong.PRS.3SG

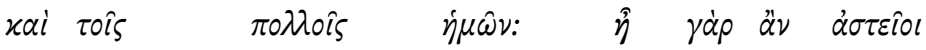
and the.DAT.PL most.DAT.Pl we.GEN.PL PTC PTC PTC witty.NOM.PL

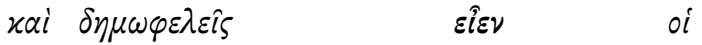
and of.general.utility.NOM.PL to.be.OPT.3PL the.NOM.PL

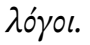
discourse.NOM.PL.

Phaedrus: Lead on, then. Socrates: Speak.

Phaedrus: Indeed, Socrates, you are just the man to hear it ...

Socrates: O noble Lysias! I wish he will write that they should be granted to the poor rather than to the rich, to the old rather than to the young, and so of all the other qualities that I and most of us have; for truly his discourse would be witty and of general utility. (P. Phdr. 227c)

Phaedrus suggests that Socrates "lead on" the conversation, but Socrates repeats that he wants Phaedrus to speak, by using the optative for a mild order (Rijksbaron 2006: 42). However, the semantics of the potential optative remain epistemic, more specifically, non-subjective epistemic. The optative signifies the conversationally given possibility that Phaedrus would speak. Its semantic value may be paraphrased as 'as you and I know, it is possible that you speak', which contextually receives the pragmatic implicature of a mild request. Phaedrus completely agrees and says that Socrates is just the man to hear it, because Lysias had written a speech on the theme of love, which said that favours should be granted to the one who is not in love. Socrates, however, subsequently expresses his wish that Lysias will say that the favours should be granted to the poor or the old, since those are qualities that Socrates himself and most of the people possess. He supports this wish by saying that Lysias' discourse would then truly be witty and of general utility. The non-subjective epistemic semantics of the optative combination is clear from the previous context. It is general knowledge to Phaedrus and Socrates that the application of Lysias' logic to the challenged persons in the world would be useful and, as witnessed by his preceding wish, Socrates subjectively marks his belief in that usefulness. 


\section{The combination with $\ddot{\alpha} \rho \alpha($ and $\hat{\eta})$}

The Classical Greek particle $\ddot{p} \alpha$ has two semantically close components-an evidential and a mirative component-of which either one may be present or both at the same time. ${ }^{49}$ On the one hand, the particle can express inferential evidentiality, meaning that the speaker's source of information for a statement is inference. This means that the validity of the statement relies on the speaker's subjective deduction from perceptible evidence, earlier experiences or (logical) reasoning. On the other hand, $\ddot{\alpha} p \alpha$ can signify the speaker's subjective surprise at the new or remarkable information which s/he has been presented with. Both subjective values share that they typically concern hindsight evaluation, which can make it difficult to determine whether an example only contains one of the semantic elements or both.

Besides semantic grounds for the propositional scope of $\alpha \rho \alpha$, there is a more formal argument that supports this classification: the particle scopes under questions (as $\hat{\eta}$ does)..$^{50}$

(12) Chremes:

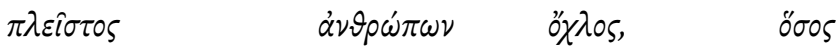

the.greatest.NOM.SG people.GEN.PL crowd.NOM.SG REL.NOM.SG

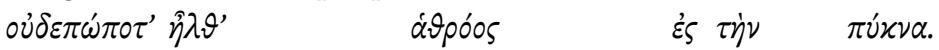
never come.IMPF.3SG together.NOM.SG to the.ACc Pnyx.ACc.sG

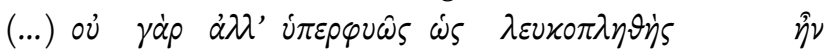
not PTC PTC strangely PTC pale-faced.NOM.SG to.be.IMPF.3SG

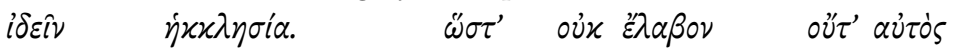
to.see.INF Assembly.NOM.SG so.that not get.AOR.1SG nor self.NOM.SG oü $\tau^{\prime}$ àd

nor other.NOM.PL many.NOM.PL

Blepyrus:

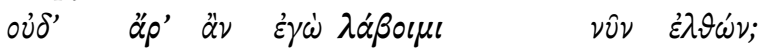

neither PTC PTC I get.OPT.AOR.1SG now go.PTCP.AOR.GEN.PL

49 I follow the definition by Allan (2015: 9) instead of Van Rooy (2016: 12-14) since Allan's treatment is more extensive, proposes a clearer connection between the two values and does not add what is in my view an unwarranted mitigating function.

$5^{\circ}$ Oddly enough, Allan 2015 only discusses this scope relation for $\hat{\eta}$ and not $\alpha$ $\alpha$. He does pay attention to the question particle $\hat{\alpha} p \alpha$. 
Chremes: A huge crowd of people showed up en masse at the Pnyx, an all-time record. (...) Really, the Assembly was awfully pale faced to behold. So I didn't get anything, and a bunch of others didn't either.

Blepyrus: So if I went there now I therefore wouldn't get anything either? (Ar. Ec. 383-387)

As with $\hat{\eta}$, the scope relations of this question can be paraphrased as 'I ask if (interrogative sentence type) whether it therefore (äp $\alpha$ ) is the case that, if I went there now, I would not get (potential optative) anything either'. 'Therefore' here signifies the subjective inference of äp $\alpha$, which Blepyrus draws from the information that Chremes gave him; that is, that the Assembly is in such a poor state that no one got anything, though people normally do get hand-outs there. Blepyrus infers that it is also pointless for him to go there. As with $\hat{\eta}$, the subjective assessment scopes over the interpersonally accessible possibility of getting something at the Assembly as usual.

An example of äp $\alpha$ with a mirative value is in example 13, where woman B's reaction to the proposal to grab some seats in front of the chairman causes dispute.

(13) Woman B:

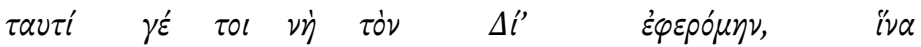
this.ACC PTC PTC PTC the.ACC Zeus.ACC bring.IMPF.1SG in.order.to

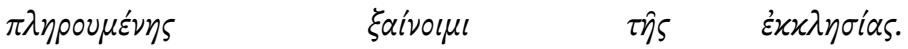
fill.up.PTCP.PRS.GEN.SG knit.OPT.PRS.1SG the.GEN Assembly.gen.sG

Praxagoras:

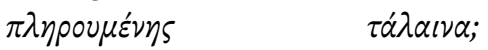

fill.up.PTCP.PRS.GEN.SG stupid.NOM.SG

Woman B:

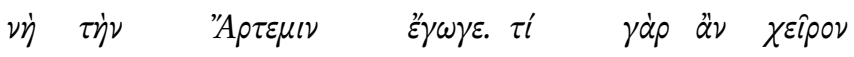

PTC the.ACC Artemis.ACC I=PTC Why.Q PTC PTC worse

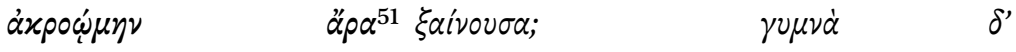

hearken.OPT.PRS.1SG PTC knit.PTCP.PRS.NOM.SG naked.NOM.PL PTC

$5^{1}$ As my analysis shows, I do not believe that it is warranted to correct $\ddot{\alpha} \rho \alpha$ to $\ddot{\alpha} \mu \alpha$ as the most recent ост by Wilson (2007) does following Dobree's conjecture (1833:232). The argument for this is threefold: the codices have $\ddot{\alpha} p \alpha$, its value fits this situation and $\ddot{p} \alpha$ actually occurs twice more often in a late position in an interrogative sentence in Wilson's text edition (Ar. Ec. 46o, 668). 
$\begin{array}{llll}\dot{\varepsilon} \sigma \tau i & \mu O v & \tau \dot{\alpha} & \pi \alpha \iota \delta i \alpha \\ \text { to.be.PRS.3SG } & \text { me.GEN } & \text { the.NOM } & \text { children.NOM.PL }\end{array}$

Woman B: (producing a knitting basket) That's exactly why I brought this along, to get some knitting done while the Assembly's filling up.

Praxagoras: Filling up, stupid?

Woman B: Sure, by Artemis. Won't I be able to listen just as well while I knit? And my kids have nothing to wear. (Ar. Ec. 86-92)

Praxagoras had instructed the women to go as man-like as they can to the Assembly, providing them, for example, with beards to let them go unnoticed. When woman B stupidly says that she brought a knitting basket to kill time when waiting for the Assembly to be filled, Praxagoras gets mad. Ignorant as she is, Woman B reacts with surprise at Praxagoras's reaction who supposes that she would be able to listen whilst also knitting. Thus, we can understand that the particle here marks the speaker's subjective surprise about the assumed given possibility that she cannot listen whilst knitting.

The non-subjectivity of the potential optative in line 90 becomes even clearer from the contrast to its occurrence without äp $\alpha$ in line 96 in Praxagora's response to Woman B.

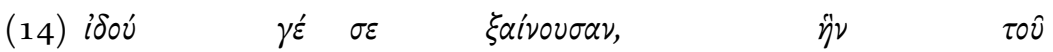

See.IMP.2SG PTC you.ACC knit.PTCP.PRS.ACC.SG REL.ACC.SG the.GEN

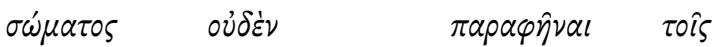

body.GEN.SG nothing.ACC.SG show.INF.PRS the.DAT

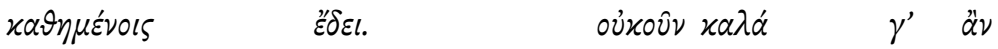

sit.PTCP.PRS.DAT.PL ought.to.IMPF.3SG PTC nice.ACC.PL PTC PTC

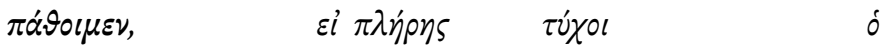

receive.OPT.AOR.1PL if full.NOM.SG happen.OPT.AOR.3SG the.NOM

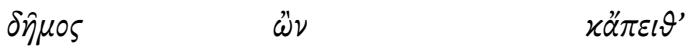

citizenry.NOM.SG to.be.PTCP.PRS.NOM and=thereafter

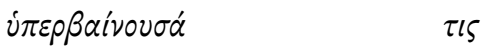

climb.over.PTCP.PRS.NOM.SG someone.NOM

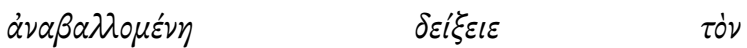

hitch.up.PTCP.PRS.NOM.SG show.OPT.AOR.3SG the.ACC Форнíбіov.

Phormisius.ACC.SG

Listen to you: knitting! When you shouldn't be showing any part of your body to the men. Wouldn't we be in a fine fix if the citizenry's all there 
and then some woman has to climb over them, hitching up her clothes and flashing her Phormisius! (Ar. Ec. 93-97)

Here Praxagoras uses the potential optative for a witty remark which the participants will understand, since they are caught up in a plan to hide their femininity.

Another indication of the epistemic accessibility of the potential optative is its occurrence in confirmatory answers.

(15) Socrates:

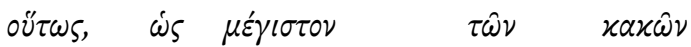

This.way that biggest.NOM.SG the.GEN evil.GEN.PL

$\tau \cup \gamma \chi \dot{\alpha} \nu \varepsilon$ oे $\nu$ to

to.be.the.case.PRS.3SG to.be.PTCP.PRS.NOM.SG the.NOM.SG

à $\delta$ ixiv.

do.wrong.INF.PRS

Polus:

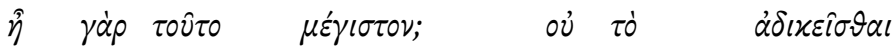

PTC PTC this.NOM biggest.NOM.SG not the.NOM suffer.wrong.INF.PRS $\mu \varepsilon \hat{i}$ ○े;

greater.NOM.SG

Socrates:

$\ddot{\eta} \varkappa \iota \tau \dot{\alpha} \quad \gamma \varepsilon$.

not.in.the.least. PTC

Polus:

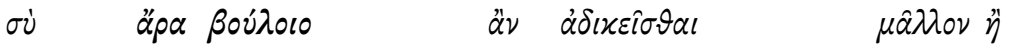

you.2SG PTC want.OPT.PRS.2SG PTC suffer.wrong.INF.PRS rather than

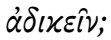

do.evil.INF.PRS

Socrates:

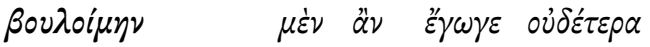

want.OPT.PRS.1SG PTC PTC I=PTC neither.ACC.PL

Socrates: In this, that to do wrong is the greatest of evils.

Polus: What, is this the greatest? Is not to suffer wrong a greater?

Socrates: By no means. 
Polus: Then would you wish rather to suffer wrong than to do it? Socrates: I would wish neither, for my own part. (P. Grg 469b-c)

When Polus questions Socrates' claim that doing evil is the greatest of evils, making committers of doing evil both pitiable and wretched, Polus infers from Socrates' stance that he would thus rather be the object of wrongdoing than the performer of it. Importantly, the possibility that he would want that is already accessible in the previous answers, but $\ddot{\alpha} \alpha \alpha$ marks that Polus subjectively applies the situation to Socrates. ${ }^{52}$ Socrates confirms that Polus is right to assume from the previous conversation that he would prefer it in that he uses the potential optative as well.

A final example that deserves treatment is the extremely rare combination of the potential optative with both $\alpha$ p $\alpha$ and $\hat{\eta}$. The rarity of this combination must stem from the fact that the non-subjective epistemic optative is combined with two subjective particles. As a result, there is a clear contextual motivation for the use of this marked option.

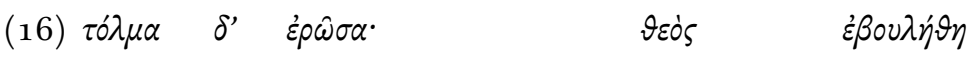

bear.up. PTC love.PTCP.PRS.NOM.SG. god.NOM.SG. want.AOR.3SG

$\tau \alpha \dot{\delta} \delta \cdot \quad \nu 0 \sigma 0 \hat{\sigma} \sigma \alpha \quad \delta^{\prime} \quad \varepsilon \hat{u} \pi \omega \varsigma \quad \tau \dot{\eta} \nu$

this.ACC be.ill.PTCP.PRS.NOM.SG PTC well somehow this.ACC

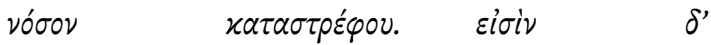

illness.ACc.sG subdue.IMP.2SG to.be.PRS.3PL PTC

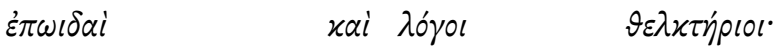

incantations.NOM.PL and words.NOM.PL enchanting.NOM.PL

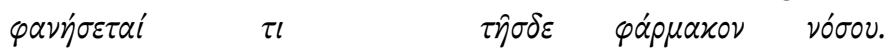

turn.up.FUT.3SG some.NOM.SG the.GEN cure.ACC.SG disease.GEN.SG

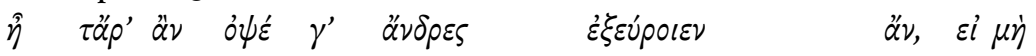

PTC PTC PTC soon PTC men.NOM.PL invent.OPT.PRS.3PL PTC if not

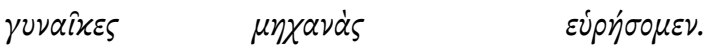

women.NOM.PL contrivances.ACC.PL discover.FUT.1PL

Bear up under your love: it was a god that willed it. And if you are ill with it, use some good measures to subdue your illness. There are incantations, and words that charm: something will turn up to cure this love. Men truly would be slow to invent such contrivances if we women do not find them. (E. Hipp. $476-481$ )

$5^{2}$ I believe that the interpersonal accessibility of the epistemic statement is what distinguishes the potential optative with evidential $\alpha \rho \alpha$ from its use with the future indicative, which presents new and insufficiently accessible knowledge. 
These lines round off a contemplative speech by the nurse on the dreadful ways of Cypris, advising Phaedra to just aim for the best that one is able to achieve. More importantly, she offers practical advice by stating that there will definitely be some kind of charm to help her. The subsequent statement with the potential optative relies on the well-known belief in Classical Greek times that women are the more mischievous sex and therefore more capable of finding the type of cures mentioned than men. ${ }^{53}$ The subjective particle $\hat{\eta}$ in my view marks that the nurse also personally believes that men will be slower in finding such a cure, an opinion partly voiced in the preceding lines and in the use of the future indicative. The following mix of $\tau 0 \mathrm{l}$ and $\alpha^{\prime} \rho \alpha\left(=\tau \alpha^{\prime} \rho^{\prime}\right),{ }^{54}$ on the one hand, mark that the validity of the statement partly relies on personal experience from which the nurse infers ( $\ddot{p} \alpha)$ that men won't be able to be as resourceful as women, while, on the other hand, asking for attention to a piece of knowledge that is of interest to Phaedra $(\tau 0 \mathrm{l})$. The whole combination of the particles and the mood thus work together to make clear to Phaedra that she can solve her problems herself without the nurse being too explicit on whether she needs to resort to malicious means. The generalizing nature of this statement thereby fits the ambiguity of the nurse's suggestions to Phaedra to take matters in her own hands.

\section{$9 \quad$ Conclusion}

In this paper I have challenged the commonly held view that the Classical Greek potential optative has a subjective epistemic semantics by, among other things, taking into account the interaction with the subjective particles $\hat{\eta}$ and äp $\alpha$. I have argued in several ways why a non-subjective epistemic semantics for the potential optative is more attractive. First, I have shown that the potential optative's lower frequency of combination with the subjective particles $\hat{\eta}$ and $\alpha$ p $\alpha$ point to a lack of affinity in (non-harmonic) combination, something which contradicts the allegedly subjective epistemic semantics for the potential optative. Second, I have demonstrated how a non-subjective approach to epistemic modality does more justice to the different kinds of epistemic modality available, in particular that of the semantics of the potential optative. This approach allows for discrimination between subjective epistemic modalities with proposition scope such as subjectively used modal verbs or subjective

53 See Barret (1964: 247) and, for example, E. IT. 1032.

54 See Allan (2015: 12-14). 
uses of the future indicative and non-subjective epistemic modalities without proposition scope such as the Classical Greek potential optative. As a result, I have been able to explain the interaction of particles with the meaning of a mood, that is, how $\hat{\eta}$ and $\ddot{p} \alpha$ specify a subjective semantic component in nonharmonic combinations with the non-subjective potential optative, added for social or rhetorical reasons to specify the speaker's personal stance. Finally, I have stressed the methodological importance of examining contrastive contexts to solidify my proposal. Especially the accurate examination of these contrastive examples and their contexts has enabled me to show the current non-subjective epistemic proposal is more satisfactory.

The results of this article provide several new research opportunities. First and foremost, I hope that the innovative contribution of this paper to the study of the interaction of particles, modality and mood will be a starting point for so-called "mood alternation" in Ancient Greek texts. ${ }^{55}$ As with tense and aspect alternation, the consecutive choice of mood by speakers ought to be investigated systematically. As we have seen with the potential optative, this alternation depends both on what is epistemically accessible to the conversational participants and on a speaker's interactive goals. An exciting starting point would be analysing the alternation between the future indicative and the potential optative with and without particles. Also, I expect that an essential analytic tool to explain the alternation of subjectively versus non-subjectively used moods will be the notion of Common Ground (Clark 1996). This notion has so far only been applied to adversative particles in Ancient Greek, ${ }^{56}$ but should in my view be applied to epistemic modality as well, because speakers adapt their mood use to what is already known by the addressee. Second, it would be rewarding to relate the non-subjective value of the potential optative in the main clause to other uses of the optative. For example, the wish optative also occasionally occurs with $\hat{\eta}$ and $\ddot{\alpha} p \alpha$ which could suggest that it has a non-subjective epistemics as well (la Roi forthc.). Finally, the particles with pragmatic values ${ }^{57}$ such as the information structural particles $\gamma(\varepsilon)$, $\delta \dot{\eta}$ and $\delta \hat{\eta} \tau(\alpha)$ or the illocutionary particles $\mu \eta^{\prime} \nu$ and $\pi \circ v$ perhaps influence the pragmatic values of the potential optative in a different way, but those questions have not been dealt with yet.

$55 \quad$ For further references, see Jary (2009).

56 See Thijs (2017), Allan (2017a) and Allan \& van Gils forthc. However, see la Roi forthc. for an application of Common Ground theory to the wish optative and its particles.

See the classification by Allan (2015). 


\section{Acknowledgments}

I would sincerely like to thank Jesús de la Villa and Rutger Allan for their help as supervisors of my research masters thesis, which provided the basis for this article. I am also grateful to the group of Ancient Greek linguists at the Autónoma University in Madrid who commented on an earlier draft of this paper. Furthermore, I thank the Philologisch Studiefonds for the financial support that enabled me to finish the article as part of research stay at the Autónoma University in Madrid. Finally, I thank the two anonymous reviewers for their helpful comments on my paper.

\section{References}

Allan, Rutger J. 20o9. Towards a typology of the narrative modes in Ancient Greek: Text types and narrative structure in Euripidean messenger speeches. In Discourse cohesion in Ancient Greek, ed. by Stéphanie J. Bakker \& Gerry C. Wakker, 171-204. Leiden/Boston: Brill.

Allan, Rutger J. 2013a. Exploring modality's semantic space: Grammaticalisation, subjectification and the case of $\dot{\varphi} \varphi \varepsilon i \lambda \omega$. Glotta 89:1-46.

Allan, Rutger J. 2013b. History as presence. Time, tense and narrative modes in Thucydides. In Thucydides between history and literature, ed. by Antonis Tsakmakis \& Melina Tamiolaki, 371-39o. Berlin/Boston: De Gruyter.

Allan, Rutger J. 2015. Classifying the Ancient Greek particles. Particle meaning, diachrony and the layered structure of discourse. Presentation at the International Colloquium of Ancient Greek Linguistics, 23-27 March, Rome.

Allan, Rutger J. 2017a. Ancient Greek adversative particles in contrast. In Pragmatic approaches to Latin and Ancient Greek, ed. by Camille Denizot \& Olga Spevak, 273301. Amsterdam/Philadelphia: John Benjamins.

Allan, Rutger J. 2017b. The history of the future: grammaticalization and subjectification in Ancient Greek future expressions. In The Greek future and its history, ed. by Theodore Markopoulos, Rutger J. Allan \& Frédéric Lambert, 43-73. Leuven: Peeters.

Allan, Rutger J. 2018. The grammaticalization of Greek particles: A Functional Discourse Grammar approach. In Ancient Greek linguistics: New perspectives, insights, and approaches, ed. by Felicia Logozzo \& Paolo Poccetti, 103-118. Berlin/Boston: de Gruyter.

Allan, Rutger J. \& Lidewij W. Van Gils. forthc. Adversative particles in Greek and Latin: A comparison.

Bakker, Stéphanie J. 2002. Futura zonder toekomst. Lampas 3:199-214. 
Barret, William S. 1964. Euripides Hippolytos. Oxford: Clarendon Press.

Bers, Victor. 1984. Greek poetic syntax in the Classical Age. Yale: Yale University Press.

Bonifazi, Anna, Annemieke Drummen \& Mark de Kreij. 2016. Particles in Ancient Greek discourse: Five volumes exploring particle use across genres. Washington, DC: Center for Hellenic Studies.

Butler, Christopher S. 2003. Structure and function: A guide to three major structuralfunctional theories. Amsterdam/Philadelphia: John Benjamins.

Bybee, Joan L., William Pagliuca \& Revere Perkins. 1994. The evolution of grammar: Tense, aspect and modality in the languages of the world. Chicago: University of Chicago Press.

Clark, Herbert. H. 1996. Using language. Cambridge: Cambridge University Press.

Crespo, Emilio. 1984. Infinitivo modal sin åv en Griego. Estudios clásicos 26: 67-74.

Crespo, Emilio. 1992. Syntaxis y semántica de las formas modales en Griego Clásico. Revista Española de Lingüística 22(2): 277-307.

Cuypers, Martijn. 2005. Interactional particles and narrative voice in Apollonius and Homer. In Beginning from Apollo: Studies in Apollonius Rhodius and the Argonautic tradition, ed. by M. Annette Harder \& Martijn Cuypers, 35-69. Leuven: Peeters.

Declerck, Renaat. 2011. The definition of modality. In Cognitive approaches to tense, aspect and epistemic modality, ed. by Adeline Patard \& Frank Brisard, 21-44. Amsterdam/Philadelphia: John Benjamins.

Denniston, John D. 1954. The Greek particles. Oxford: Oxford University Press.

Denizot, Camille. 2011. Donner des ordres en Grec Ancien. Rouen: Publications des universités de Rouen et du Havre.

Dik, Helma. 2014. 'Most likely to succeed': Degree adverbs specifying probability in Classical Greek. Greek, Roman, and Byzantine Studies 54: 599-616.

Dik, Simon C. 1997. The theory of Functional Grammar. 2 vols. Berlin: de Gruyter.

Dobree, Peter P. \& Jacobo Scholefield. 1833. Adversaria. London: Cantabrigiae.

Drummen, Annemieke. 2013. A constructionist approach to the potential optative in Classical Greek drama. Glotta 89: 68-108.

Gardes-Tamine, Joëlle. 1987. Introduction à la syntaxe (suite): Modes, temps et aspects. L'Information grammaticale 33: 37-40.

Gerö, Eva C. 200o. The usage of $\alpha \dot{\alpha} v$ and $x \varepsilon$ in Ancient Greek: Towards a unified description. Glotta 74: 177-191.

Goodwin. William W. 1867 (1965). Syntax of the moods and tenses of the Greekverb. New York: Ginn.

de Haan. Ferdinand. 20o6. Typological approaches to modality. In The Expression of Modality, ed. by William Frawley, 1-26. Berlin: de Gruyter.

Hengeveld, Kees \& John L. Mackenzie. 20o8. Functional Discourse Grammar. A typologically based theory of language structure. Oxford: Oxford University Press.

Hengeveld, Kees. 1988. Illocution, mood and modality in a Functional Grammar of Spanish. Journal of semantics 6(1): 227-269. 
Jary, Mark. 20o9. Relevance, assertion and possible worlds: A cognitive approach to the Spanish subjunctive. In Utterance interpretation and cognitive models, ed. by Philippe de Brabanter \& Mikhail Kissine, 235-277. Bingley: Emerald.

Kühner, Raphael \& Bernhard Gerth. 1904. Ausführliche Grammatik der griechischen Sprache, Teil 2 Band 2. Hannover: Hahn.

Lanski, Alison. 2013. Emphatic negation and the potential optative. Mnemosyne 66(4): $777-783$.

Logozzo, Felicia \& Paolo Poccetti (eds.). 2018. Ancient Greek linguistics: New perspectives, insights, and approaches. Berlin/Boston: de Gruyter.

Lyons, John. 1977. Semantics, vol. 2. Cambridge: Cambridge University Press.

Martínez Vázquez, Rafael. 1995. Tiempo relativo en griego antiguo. Philologia Hispalensis 10: $175^{-197 .}$

Narrog, Heiko. 2012. Modality, subjectivity, and semantic change: A cross-linguistic perspective. Oxford: Oxford University Press.

Nuyts, Jan. 2001. Epistemic modality, language, and conceptualization: a cognitive pragmatic perspective. Amsterdam: John Benjamins.

Nuyts, Jan. 2002. Grounding and the system of epistemic expressions in Dutch: A cognitive functional view. In Grounding: The epistemic footing of deixis and reference, ed. by Frank Brisard, 433-466. Berlin: de Gruyter.

Nuyts, Jan. 20o6. Modality: Overview and linguistic issues. In The expression of modality, ed. by William Frawley, 1-26. Berlin: de Gruyter.

Palmer, Frank R. 1986. Mood and modality. Cambridge: Cambridge University Press.

Revuelta Puigdollers, Antonio. 2005. Modo y modalidad en Griego Antiguo: La negacion. Sintaxis Griega, ed. by M. Dolores Jiménez López, 1-27.

Revuelta Puigdollers, Antonio. 2017. Illocutionary force and modality: How to tackle the issue in Ancient Greek. Pragmatic approaches to Latin and Ancient Greek, ed. by Camille Denizot \& Olga Spevak, 17-43. Amsterdam/Philadelphia: John Benjamins.

Rijksbaron, Albert (ed.). 1997. New approaches to Greek particles. Proceedings of the colloquium held in Amsterdam, 4-6January 1996, to honour C.J. Ruijgh on the occasion of his retirement. Amsterdam: Gieben.

Rijksbaron, Albert. 2006. The syntax and semantics of the verb in Classical Greek. Amsterdam: Gieben.

la Roi, Ezra. forthc. The variation of Classical Greek wishes: A Functional Discourse Grammar and Common Ground approach, Glotta.

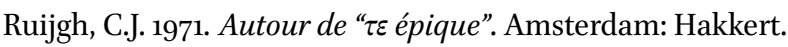

Ruiz Yamuza, Emilia. 200o. Objective and subjective modality satellites in Ancient

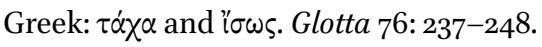

Ruiz Yamuza, Emilia. 20o6. Modalidades subjetivas y objetivas y clases de palabras. Word classes and related topics in Ancient Greek, ed. by Emilio Crespo, Jesús de la Villa \& Antonio Revuelta Puigdollers, 313-33o. Leuven: Peeters. 
Ruiz Yamuza, Emilia. 2013. Mood and modality. Encyclopedia of Ancient Greek language and linguistics, ed. by Georgios K. Giannakis, 452-459. Leiden/Boston: Brill.

Schwyzer, Eduard \& Albert Debrunner. 1950. Griechische Grammatik. Band 2. Munich: C.H. Beck.

Sicking, Christiaan M.J. \& Jan M. Van Ophuijsen. 1993. Two studies in Attic particle usage. Leiden/New York/Cologne: Brill.

Slotty, Friedrich. 1915. Der Gebrauch des Konjunktivs und Optativs in den griechischen Dialekten. Göttingen: Huth.

de Smet, Hendrik \& Jean-Christoph Verstraete. 20o6. Coming to terms with subjectivity. Cognitive Linguistics 17(3): 365-392.

Smyth, Herbert W. 1920 (1963). Greek grammar. Harvard: Harvard University Press.

Thijs, Kees. 2017. The Attic particle $\mu \eta^{v}$ : Intersubjectivity, contrast and polysemy. Journal of Greek Linguistics 17: 73-112.

Tronci, Liana. 2017. On the distribution of some interactive/conclusive discourse markers in Plato's Theaetetus. In Pragmatic approaches to Latin and Ancient Greek, ed. by Camille Denizot \& Olga Spevak, 213-234. Amsterdam/Philadelphia:John Benjamins.

Van Rooy, Raf. 2016. The relevance of evidentiality for Ancient Greek: Some explorative steps through Plato. Journal of Greek Linguistics 16: 3-46.

Verstraete, Jean-Christoph. 2004. The problem of subjective modality in the Functional Grammar model. A new architecture for Functional Grammar, ed. by John Lachlan, Mackenzie \& Maria Gómez-González, 243-274. Berlin: de Gruyter.

de la Villa, Jesús. 2017. The future optative and the expression of relative tense in Ancient Greek. In The Greek future and its history, ed. by Theodore Markopoulos, Rutger J. Allan \& Frédéric Lambert, 73-86. Leuven: Peeters.

Wakker, Gerry C. 1997. Emphasis and affirmation: Some aspects of $\mu$ 'v $\nu$ in tragedy. In New approaches to Greek particles. Proceedings of the Colloquium held in Amsterdam, 46 January 1996, to honour C.J. Ruijgh on the occasion of his retirement, ed. by Albert Rijksbaron, 209-231. Amsterdam: Gieben.

Wakker, Gerry C. 2013. Conditionals. Encyclopedia of Ancient Greek language and linguistics, ed. by Georgios K. Giannakis. Leiden/New York: Martinus Nijhoff/Brill.

Willmott, Jo. 2007. The moods of Homeric Greek. Cambridge: Cambridge Classical Studies.

Wilson, Nigel G. 2007. Aristophanis Fabulae. Oxford: Oxford University Press.

Zingg, Emanuel. 2017. Futur nach åv bei Isokrates. Glotta 93: 290-313. 